\title{
Reliability assessment of functional clothing for lactating Women
}

\author{
NISHA ARYA, V. SINGH AND N. YADAV
}

Received: 28.04.2017; Revised: 30.09.2017; Accepted: 16.10.2017

See end of the paper for authors' affiliations

\section{NISHA ARYA}

Department of Textile and Apparel

Designing, I.C. College of Home Science,

C.C.S. Haryana Agricultural University,

HISAR (HARYANA) INDIA

Email : nishasangwan@gmail.com ay woman faces various psychosocial barriers to breastfeeding, ABSTRACT : The modern day worion
in addition to the emotional and physical to assess clothing requirements of lactating mothers. The identified clothing requirements were incorporated in garment challenges. There is great potential for the development and improvement of apparel for breastfeeding mothers. The aim of this study was to design and develop functional clothing for a lactating woman. A questionnaire was developed for personal interview designs. After designing preference was taken by lactating mothers and top six preferred designs were constructed and given to the lactating women for wear trial. The related data highlights that design 1 with jacket was ranked $1^{\text {st }}$ on overall basis (4.68) followed by design 3 having side pleat (Rank II, 4.59), design 2 with horizontal opening (Rank III, 4.47) and design 6 with yoke (Rank IV, 4.32). Design 6 with princess line and 4 with centre long front opening having average mean score 4.20 and 4.13 , respectively were assessed next in their rank orders. It can be concluded from the data that subject was satisfied with the functional designs. This type of designing and construction of functional clothing can boost up the confidence of lactating mothers to breastfeed in the public places and thus ultimately breaking psychosocial barriers to breastfeeding and also enhance psychological comfort by lifting their self esteem.

KEY WORDS: Breastfeeding, Psycho social, Lactating, Functional clothing, Psychological

- HOW TO CITE THIS PAPER : Arya, Nisha, Singh, V. and Yadav, N. (2017). Reliability assessment of functional clothing for lactating women. Asian J. Home Sci., 12 (2) : 402-407, DOI: 10.15740/HAS/AJHS/ 12.2/402-407. 